\title{
What Can Zebrafish Teach Us About Fear?
}

Maryana Pereira Pyterson ${ }^{1}$, Pedro de Tarcio Guedes ${ }^{2}$, Saulo Rivera Ikeda ${ }^{2}$, Tainá Dias ${ }^{2}$, Wilker Nascimento ${ }^{2}$, Monica Gomes Lima-Maximino ${ }^{2}$, Caio Maximino*1

1 - Laboratório de Neurociências e Comportamento "Frederico Guilherme Graeff", Instituto de Estudos em Saúde e Biológicas, Universidade Federal do Sul e Sudeste do Pará - Brazil

2 - Laboratório de Neurofarmacologia e Biofísica, Departamento de Morfologia e Ciências Fisiológicas, Campus Marabá, Universidade do Estado do Pará - Brazil

\section{* Corresponding author}

Caio Maximino

Laboratório de Neurociências e Comportamento, Instituto de Estudos em Saúde e Biológicas, Universidade Federal do Sul e Sudeste do Pará - Campus III

Av. dos Ipês S/N, Marabá/PA, Brazil

cmaximino@unifesspa.edu.br 


\begin{abstract}
Fear can sometimes paralyze us, and it can sometimes be exciting; for some people, fear is so crippling it can significantly mix up their lifes! We understand a little bit about how the brain acts when we are afraid, mainly by studying the brains of animals. Recently, surprising findings were made using a humble animal, the zebrafish - a small aquarium fish that in the past has helped scientists figure out how our organs develop. Zebrafish are useful because they develop quickly, reproduce richly, and have brains which are similar to ours. They also produce what we call an "alarm substance" that alerts shoalmates when one of them has been injured; when they smell this substance in the water they act as if they are very scared. When this happens, they release serotonin in their brains, a neurotransmitter that acts as a light switch, making them less afraid but more cautious - as if trying to figure out if a predator is there or not. Hopefully, finding more about how the zebrafish brains process this serotonin signal can help scientists develop better treatments for mental disorders that are associated with fear.
\end{abstract}

Keywords: Fear; Zebrafish; Alarm substance; Animal model; Serotonin

\title{
1. Introduction
}

In our everyday experience, we very often feel afraid: of dangerous stuff like snakes and other venomous animals, of heights, of bad people, and so on. Fear is an emotion observed in all animals - including humans - that allows a quick and momentary state of alertness of the organism when perceiving something that can do you harm. The tension caused by fear has the function of cutting down the consequences of exposure to a dangerous situation. Fear is generated by parts of the brain, such as the amygdala, hypothalamus, and a region called the periaqueductal gray area, that act together with the sense organs (sight, hearing, smell, touch and taste) to produce a corresponding behavior to danger [1]. Importantly, other things that can signal the presence of a dangerous thing - including objects and landscapes - can also trigger the state of fear; who among us has not been startled by a loud noise, or by a shadow we briefly thought was an animal, no matter how irrational that was? In this context, this emotion has an important role in the everyday life of animals, because fear serves as an instinctive protection for the individual to recognize potential and real risks.

Fear is also important because, when excessive, can be part of many different mental disorders called anxiety disorders. While many researchers argue that fear and anxiety are different things, both involve this negative feeling of danger. Anxiety disorders are one of the major health problems in the world today, and currently available treatments arenot very good. New discoveries about fear and the brain could help diminish this problem.

\section{Using animals to study fear}

We know a little bit about fear from studying humans - for example, by using neuroimaging to try to figure out what is going in the brains of people while they are being scared (Figure 1) - but it is not an easy task. First, current neuroimaging 
technology is only able to look for activity up to a certain depth, and deeper regions in the brain (including important regions such as the periaqueductal gray area) are difficult to observe. Moreover, it is actually difficult to make people afraid in the lab, because most of the things that make us really afraid can also damage us. Finally, it is very hard to find people that volunteer to such experiments! As a result, much of what we know about fear and how the brain controls this emotion comes from research with animals.

Animals are used in scientific research to simulate different behavioral processes that affect humans. While we tend to think of rats and mice when we think about lab animals, many different species are used: flies, rabbits, dogs, and fish. Some researchers argue that focusing only in rodents (rats and mice) decrease the probability of discovering something that can illuminate what we know about the human brain [2]. These ideas prompted neuroscientists to look for other species as new models of research imitating humans. Swiftly swimming in these waters is the zebrafish, an animal model widely used in the field of genetics, embryology, and behavior. Aiming to discover new ways of treating human diseases, the humble zebrafish also enables a more detailed monitoring of the disease in the case, which is one of the best advantages of using zebrafish as an animal model. All this because of their genetic and anatomical similarities with the human being (Figure 2).

\section{The alarm substance of zebrafish}

The main advantage of using zebrafish to study fear is that, as other fish from its order, they produce special substances in its skin that signal to the other members of the shoal that one of them has been wounded, prompting the others to be cautious. When the skin is damaged by, for example, a predator, alarm substance is released, and shoal-mates can smell it. The "smell of danger" makes the shoal-mates behave as if they are afraid: they tighten the shoal, to increase protection; they also swim more erratically (zig-zaglike), to decrease the probability of being eaten and to make the substratum float in the water; and they sometimes freeze in place, decreasing the probability that the predator sees them [3]. Through these behaviors, neuroscientists and behavioral scientists can know whether or not the fish is afraid, and then use this inference to better understand how the brain acts when frightened.

One of the findings that were made in zebrafish focuses on the neurotransmitter serotonin. Neurotransmitters are special chemicals that are released by neurons and other brain cells when they are excited; for communication between neurons to occur, nerve impulses are initiated in one neuron and conducted by the axon, leading to the release of these chemicals. Neurotransmitters then initiate electrical activity in other neurons, or lead to muscle contraction, or release of hormones in the blood stream. Serotonin is perhaps best known as a "happiness hormone", because antidepressants act by boosting serotonin in the brain, but nothing could be farther from the truth: in fact, there is good evidence that serotonin increases anxiety, although it appears to decrease fear.

Researchers now believe that serotonin is involved in the fear generated by alarm substance in zebrafish. In 2014, researchers discovered that alarm substance induces the release of serotonin in the zebrafish brain when the animals no longer smell the substance [4], making the animals more cautious, as if trying to determine whether or not there is a predator around. But how does serotonin acts to produce this effect? In 
another experiment, these researchers also found that one of serotonin's receptors, 5HT1A, does not seem to be involved in this "extra caution" that appears after the alarm substance is no longer detectable [4]. Evidence for the participation of this receptor comes from another study [5] that found that injecting a drug that blocks it - not allowing serotonin to produce its usual effect - made animals more afraid when in contact with the alarm substance. These authors also found that blocking other serotonin receptors, from the 5-HT2 family, produce a similar effect, suggesting that the serotonergic system counteracts the initial effects of alarm substance, but may also be involved in increasing the subsequent cautiousness that is observed when the substance is no longer present.

\section{Conclusion}

Our brains (and the brains of zebrafish!) deal with scaring situations every day. Your brain and your body are always at the ready to deal with frightening things in a way that preserves you, but does not make you "cry wolf" when threat is not certain. With the help of serotonin, we can switch between these strategies: running away from a certain danger, or cautiously investigating - and worrying! - whether there is actual danger. It is possible that studying more about serotonin and other neurotransmitter in the zebrafish brain can help us produce new drugs to treat diseases of fear; hopefully, these insights can help us find a cure for anxiety disorders!

1. Bezdek KG, Telzer EH. Have no fear, the brain is here! How your brain responds to stress. Front Young Minds (2017) 5:71. doi:10.3389/frym.2017.00071

2. Gerlai R. Fish in behavior research: Unique tools with a great promise! $J$ Neurosci Methods (2014) doi:10.1016/j.jneumeth.2014.04.015

3. Maximino C, Silva RX do C, Campos K dos S, Oliveira JS de, Rocha SP, Pyterson MP, Souza DP dos S, Miranda LF, Ikeda SR, Pimentel AFN, et al. Sensory ecology of Ostariophysan alarm substances. preprints.org (2018) doi:10.20944/preprints201803.0279.v1

4. Maximino C, Lima MG, Costa CC, Guedes IML, Herculano AM. Fluoxetine and WAY 100,635 dissociate increases in scototaxis and analgesia induced by conspecific alarm substance in zebrafish (Danio rerio Hamilton 1822).

Pharmacol Biochem Behav (2014) 124C:425-433.

doi:10.1016/j.pbb.2014.07.003

5. Nathan FM, Ogawa S, Parhar IS. Kisspeptin 1 modulates odorant-evoked fear response via two serotonin receptor subtypes (5-HT1A and 5-HT2) in zebrafish. $J$ Neurochem (2015) 133:870-878. doi:10.1111/jnc.13105 


\section{Figure 1}
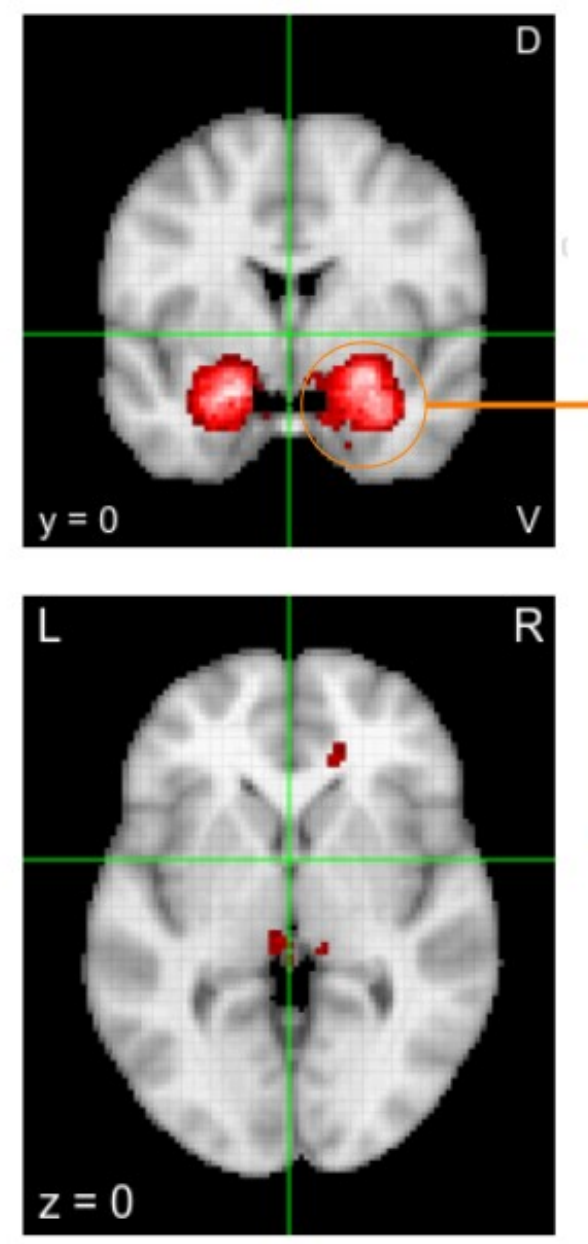

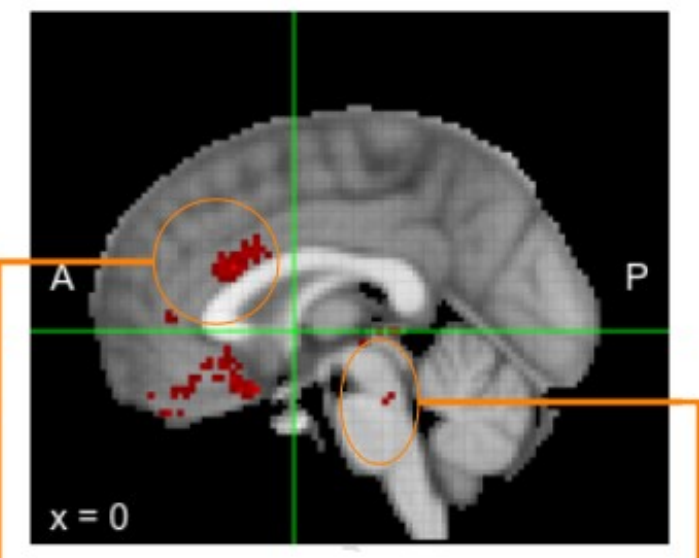

- These are some structures that participate in human fear, as assessed by neuroimaging

- The amygdala is a set of structures that detects threatening stimuli and integrates responses

- The cingulate cortex has an important for emotion assessment and emotionrelated learning

- The midbrain is involved in fight-flight-freeze responses 


\section{Figure 2}

\section{Some reasons to study zebrafish}

- Transparent embryos with rapid development

-Major organs start to form 24 hours after fertilization!

- High fecundity and short generation time

-A zebrafish couple lays 100-300 eggs every week!

-Embryos start to behave consistently 4-6 days after fertilization

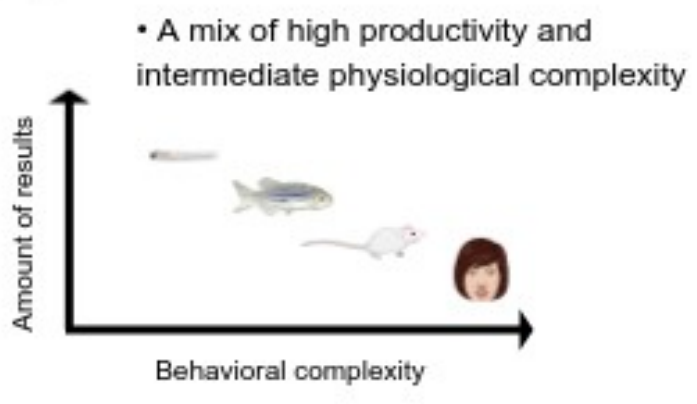

- A mix of high productivity and

Behavioral complexity

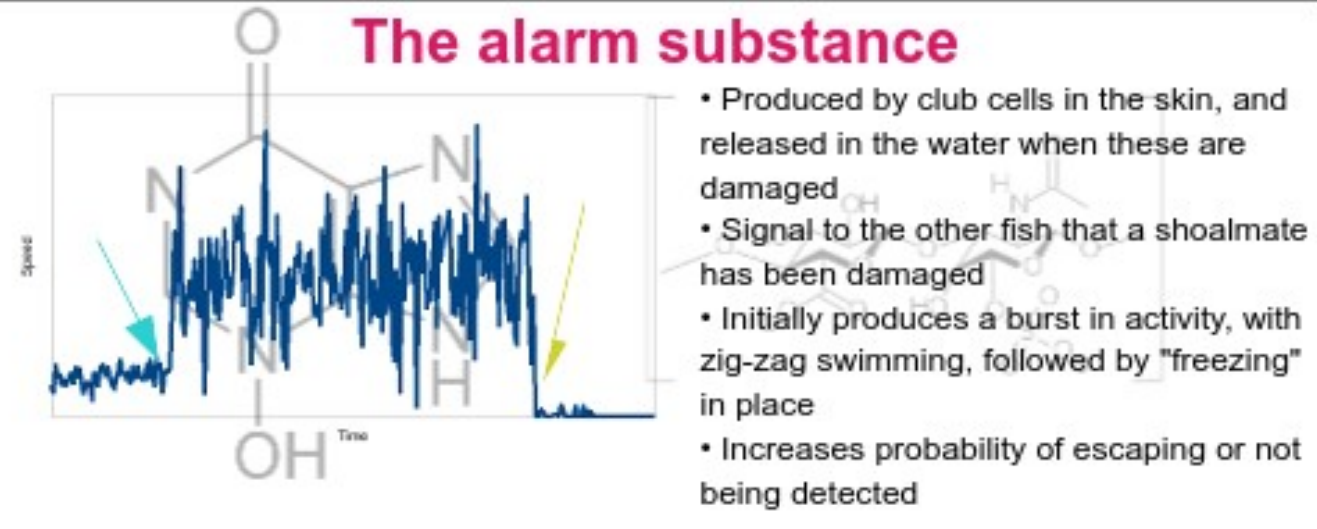

